\title{
A CROSS-SECTIONAL STUDY ON THE HEALTH RELATED QUALITY OF LIFE IN PATIENTS WHO COMPLETE TREATMENT FOR PULMONARY TUBERCULOSIS
}

\author{
Vijay Nair1, Shivaji Patil2, Asha Pratinidhi³, Bhagwan Pawar', Alaknanda Jadhav5, Rajesh Gaikwad', Vaishali Raje ${ }^{7}$ \\ ${ }_{1}^{1}$ Assistant Professor, Department of Pulmonary Medicine, KIMSDU, Malkapur, Karad, Maharashtra, India. \\ ${ }^{2}$ Associate Professor, Department of Pulmonary Medicine, KIMSDU, Malkapur, Karad, Maharashtra, India. \\ 3 Professor, Emeritus, Department of Preventive and Social Medicine, KIMSDU, Malkapur, Karad, Maharashtra, India. \\ ${ }^{4}$ District Health Officer, Satara, Maharashtra, India. \\ ${ }^{5}$ Senior Medical Officer, T. B. Centre, Satara, Maharashtra, India. \\ ${ }^{6}$ District Tuberculosis Officer, Satara, Maharashtra, India. \\ 7Professor, Department of Preventive and Social Medicine, KIMSDU, Malkapur, Karad, Maharashtra, India.
}

\section{BACKGROUND}

\section{ABSTRACT}

Pulmonary Tuberculosis (PTB) is a chronic infection, which has its effect on the lung even after it has been cured with antitubercular medications. In this study, we have tried to objectively study its effect on the lung function and health related quality of life.

\section{MATERIALS AND METHODS}

Four hundred and forty three patients who fulfilled the inclusion criteria during the allotted study period were enrolled in the study after obtaining their due consent. Chest radiographs were analysed and were ranked according to Willcox into three degrees. Pulmonary function test was done following American Thoracic Society [ATS] protocol. Marathi version of St. George's Respiratory Questionnaire [SGRQ] was used to assess the quality of life. All the data was analysed using chi-square, ANOVA and unpaired ' $t$ ' test using SPSS Software 12.

\section{RESULTS}

The mean age of the patients were $46.2 \pm 17.6(18-86)$ with IQR 32. Chest $\mathrm{x}$-ray was graded from I to III with the majority falling in Degree I (48.76\%) followed by Degree II (32.73\%) and Degree III (18.51\%). Spirometry was normal in 152 (34.3\%) patients. The predominant lung function abnormality was restriction type of disease in 155 (35\%) patients followed by mixed pattern 90 (20.3\%) and obstruction 46 (10.4\%). St Georges Respiratory Questionnaire (SGRQ) scores were higher in the study subjects. The mean SGRQ scores for symptom, activity and impact were 22.44, 33.02 and 19.44 .

\section{CONCLUSION}

From the present study, it was concluded that patients who have suffered from pulmonary tuberculosis have poor quality of life scores. Health related quality of life scores (SGRQ) had good correlation with chest x-ray findings and spirometric analysis. Thus, all patients post pulmonary tuberculosis should undergo pulmonary rehabilitation for better quality of life.

\section{KEY WORDS}

Pulmonary Tuberculosis, St. Georges Respiratory Questionnaire, Health Related Quality of Life, Forced Expiratory Volume.

HOW TO CITE THIS ARTICLE: Nair V, Patil S, Pratinidhi A, et al. A cross-sectional study on the health related quality of life in patients who complete treatment for pulmonary tuberculosis. J. Evolution Med. Dent. Sci. 2018;7(25):2939-2943, DOI: $10.14260 /$ jemds/2018/662

\section{BACKGROUND}

Tuberculosis (TB) is a chronic infection with very high rates of morbidity and mortality. India accounts for one-fifth of the total global TB incidence with 1.9 million new cases occurring every year and 0.87 million of these being infectious smearpositive cases. In India every year an estimated 2.76 lakh deaths occur as a result of TB. The most affected by disease incidence are the people who belong to the most economically productive age group of 15 - 60 years.

'Financial or Other Competing Interest': Project was joint venture between RNTCP and Krishna Institute of Medical Sciences Deemed University and was funded by RNTCP.

Submission 10-05-2018, Peer Review 03-06-2018,

Acceptance 09-06-2018, Published 18-06-2018.

Corresponding Author:

Dr. Vijay Nair,

A8/30, Sunder Nagar, Kalina, Santacruz (E),

Mumbai-400098, Maharashtra, India.

E-mail: drvijaynair@gmail.com

DOI: $10.14260 /$ jemds $/ 2018 / 662$

\section{(c) $($ ) $\ominus$}

Involvement of the airways in Pulmonary Tuberculosis leads to mucosal oedema, hypertrophy and hyperplasia of mucous glands, increased mucus secretion and smooth muscle hypertrophy. Once cicatricial fibrosis sets in, there is a reduction of total lung capacity. ${ }^{1}$ The daily activities are affected as many of the post-tuberculosis patients have limited exercise tolerance and significant disability. ${ }^{2}$ The presence of extensive residual lung lesions following tissue destruction, cor-pulmonale and susceptibility to opportunistic infections, may be a predictor of permanent disability leading to reduced quality of life. ${ }^{3}$ The suffering caused by tuberculosis (TB) has been acknowledged since ages, ${ }^{4}$ though the use of health-related quality of life (HRQOL) in the evaluation of such patients is a much more recent development. ${ }^{5}$ Those with active TB when compared to a comparator population, the evidence suggests that active TB is associated with a lower health status than found in subjects without Tuberculosis. ${ }^{6}$ We know very little about the longterm quality of life of those who have completed TB treatment and none of the studies that have collected 
longitudinal data during TB treatment followed up post treatment completion. Thus, a study like this would help to touch those aspects of tuberculosis management, which in future may have an impact on the person's quality of life and which is usually ignored in the programmatic settings.

\section{Primary Objectives}

- To estimate the health related quality of life after completion of anti-tubercular medications for Pulmonary Tuberculosis.

\section{Secondary Objectives}

- To estimate the lung function abnormalities among pulmonary tuberculosis patients who have successfully completed treatment in RNTCP.

- To determine the association between lung function and quality of life in pulmonary tuberculosis patients who have successfully completed treatment in RNTCP.

\section{MATERIALS AND METHODS \\ Study Design}

It is a cross-sectional study. The study participant are individuals who have been suffering from tuberculosis and have been declared cured after completing DOTS RNTCP regimen.

\section{Study Population}

The residents of Satara, Maharashtra.

\section{Inclusion Criteria}

Age group of 18 - 60 years, who are able to perform spirometry, who have successfully completed treatment and have been declared cured.

\section{Exclusion Criteria}

Patients who are unable to perform spirometry or those with clinical features of active pulmonary tuberculosis.

\section{Sample Size}

The study was done in 2016 - 18 time period. Sample size of 410 subjects was calculated from the mean and standard deviation obtained from a previous similar study. ${ }^{7}$

Formula used $=\mathrm{n}=\frac{\mathrm{Z}^{2} \mathrm{x}(\mathrm{SD})^{2}}{(\mathrm{~L})^{2}}$
$\mathrm{z}$. $=$ Relative confidence interval $=1.96$
$\mathrm{~L}=$ Error observed
$\mathrm{N}=\frac{(1.96)^{2} \mathrm{x}(20.65)^{2}}{(2)^{2}}$
$\mathrm{~N}=410$

\section{Sampling Procedure}

Consecutive sample technique was used in this study. All those who have suffered from pulmonary tuberculosis and have been declared cured in the past five years were referred from various district health centres in Satara to Krishna Institute of Medical Sciences, Karad, Satara. Those patients who could come to Krishna Institute of Medical Sciences and fulfilled the inclusion criteria were enrolled into our study.

\section{Data Collection Procedure}

The interviewers were staff of Krishna Institute of Medical Sciences. They were trained for the methods of uniform data collection. Interviews were conducted in the local language, [Marathi]. The nature and purpose of the study was explained in detail to all the study patients and written informed consent was obtained. Proforma was designed and ethical committee clearance was obtained. Pre-coded questionnaire to collect data on the demographic characteristics were used. Marathi version of St. Georges Respiratory Questionnaire [SGRQ] was used to assess the quality of life. The SGRQ is valid for use in post tuberculosis patients. It is in two parts. Part I produces the Symptoms score and Part 2 the Activity and Impacts scores. Total score is also obtained, which would be analysed. The normative values for a general population studied in Spain recommended in SGRQ manual is used for comparison as the data pertaining to SGRQ scores in general population in India is not available. ${ }^{21}$ Chest radiographs were analysed and was ranked according to Willcox. ${ }^{8}$ The lung fields were divided into six zones and radiographic results to be classified by degree-

- Degree I- With minimum involvement of only one zone without cavitation.

- Degree II- Involving of two or three areas or zones with cavitation.

- Degree III- Severe involvement in more than three zones with or without cavitation.

Pulmonary function test was done following American Thoracic Society [ATS] protocol. ${ }^{9}$

\section{Statistical Analysis}

Significance of variables was assessed using $p$-value and $p$ value of less than 0.05 was considered to be statistically significant. All the data were analysed using chi-square, ANOVA and unpaired ' $\mathrm{t}$ ' test using SPSS Software 12 .

\section{RESULTS}

There were 443 patients who fulfilled the inclusion criteria and were enrolled into the study. The mean age of the patients were $46.2 \pm 17.6(18-86)$ with IQR 32 . Males were 259 (58.50\%) and females were 184 (41.50\%). Among the enrolled patients, majority resided in the rural areas 350 (79\%) as compared to urban areas 93 (21\%).

Mean BMI of the patients in the study was $19.03 \pm 3.36$ (11.4 - 30.1) with IQR 4.05.

209 (47.20\%) patients had a normal BMI and 207 $(46.70 \%)$ patients were underweight.

Majority of patients were non-smokers, 429 (96.8\%) as compared to smokers 14 (3.20\%). Similarly, majority of the patients were non-alcoholic 401 (96.8\%).

The mean time taken to start treatment was $33.73 \pm 27.8$ (7 - 180) with IQR 15.

In this study, chest $\mathrm{x}$-ray was graded from I to III with Degree I representing minimal changes and Degree III severe findings. Majority fell into Degree I (48.76\%) followed by Degree II (32.73\%) and Degree III (18.51\%). 
Spirometry was performed on all 443 patients. Spirometry was normal in $152(34.3 \%)$ patients. The predominant lung function abnormality was restriction type of disease in 155 (35\%) patients. Mixed pattern was seen in $90(20.3 \%)$ patients and obstruction was seen in $46(10.4 \%)$ patients. St. George Respiratory Questionnaire (SGRQ) was used to assess the quality of life. SGRQ scale scores in the study population according to sex, smoking behaviour, chest $\mathrm{x}$-ray, FEV1\% predicted and spirometry diagnosis were compared. The mean SGRQ scores for symptom, activity and impact were 22.44, 33.02 and 19.44 which were high.

\begin{tabular}{|c|c|}
\hline Age & $46.22 \pm 17.60$ \\
\hline Male $\%$ & $259(58.50 \%)$ \\
\hline Female $\%$ & $184(41.50 \%)$ \\
\hline BMI & $19.03 \pm 3.36$ \\
\hline Underweight & $207(46.70 \%)$ \\
\hline Normal & $209(47.20 \%)$ \\
\hline Overweight & $24(5.40 \%)$ \\
\hline Obese & $3(0.70 \%)$ \\
\hline Chest X-ray Grading & $216(48.76 \%)$ \\
\hline Degree I & $145(32.73 \%)$ \\
\hline Degree II & $82(18.51 \%)$ \\
\hline Degree III & $1.95 \pm 0.80$ \\
\hline PFT & $1.56 \pm 0.73$ \\
\hline FVC & $68.68 \pm 24.49$ \\
\hline FEV1 & \\
\hline FEV1\% & \\
\hline Table 1. Characteristics of the Patients who were & Investigated
\end{tabular}

\begin{tabular}{|c|c|c|c|c|}
\hline & Symptoms & Activity & Impact & Overall \\
\hline $\begin{array}{c}\text { Mean observed } \\
\text { values }\end{array}$ & 22.44 & 33.02 & 19.44 & 23.82 \\
\hline SD & 22.78 & 33.42 & 22.41 & 23.48 \\
\hline Table 2. Distribution Characteristics and Reliability \\
Estimates SGRQ Scales in the Study Population
\end{tabular}

\begin{tabular}{|c|c|c|c|c|c|}
\hline & & Symptom & Activity & Impact & Overall \\
\hline $\begin{array}{c}\text { Mean } \\
\text { Normal } \\
\text { Value }\end{array}$ & & 12 & 9 & 2 & 6 \\
\hline \multirow{4}{*}{ Sex } & Male & $\begin{array}{c}23.19 \\
\pm(23.34)\end{array}$ & $\begin{array}{c}33.57 \\
\pm(34.08)\end{array}$ & $\begin{array}{l}20.14 \pm \\
(23.79)\end{array}$ & $\begin{array}{c}24.42 \\
\pm(24.66)\end{array}$ \\
\hline & Female & $\begin{array}{l}21.38 \pm \\
(21.99) \\
\end{array}$ & \begin{tabular}{|l|}
$32.23 \pm$ \\
$(32.54)$ \\
\end{tabular} & $\begin{array}{c}18.46 \\
\pm(20.32) \\
\end{array}$ & $\begin{array}{c}22.97 \\
\pm(21.74) \\
\end{array}$ \\
\hline & $\begin{array}{c}\mathrm{T} \\
\text { statistic }\end{array}$ & 0.83 & 0.42 & 0.80 & 0.65 \\
\hline & P value & 0.41 & 0.68 & 0.43 & 0.51 \\
\hline \multirow{4}{*}{ 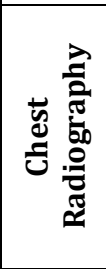 } & I & $\begin{array}{l}12.64 \pm \\
(17.35)\end{array}$ & $\begin{array}{l}15.25 \pm \\
(24.55)\end{array}$ & $\begin{array}{c}9.50 \pm \\
(15.65)\end{array}$ & $\begin{array}{c}11.44 \pm \\
(16.03)\end{array}$ \\
\hline & II & $\begin{array}{l}28.22 \pm \\
(22.50)\end{array}$ & $\begin{array}{l}41.87 \pm \\
\text { (31.78) }\end{array}$ & $\begin{array}{l}23.57 \pm \\
(22.11)\end{array}$ & $\begin{array}{l}29.68 \pm \\
(22.21)\end{array}$ \\
\hline & III & $\begin{array}{l}38.03 \pm \\
(23.89)\end{array}$ & $\begin{array}{l}64.16 \pm \\
(27.10)\end{array}$ & $\begin{array}{l}38.33 \pm \\
(23.77)\end{array}$ & $\begin{array}{c}46.07 \pm \\
(21.85)\end{array}$ \\
\hline & $F$ & 54.47 & 104.67 & 69.15 & 104.95 \\
\hline & \begin{tabular}{|l|} 
P value \\
\end{tabular} & 0.0 & 0.0 & 0.0 & 0.0 \\
\hline \multirow{3}{*}{$\sum^{0}$} & $<80$ & $\begin{array}{l}28.27 \pm \\
(23.57)\end{array}$ & $\begin{array}{l}42.52 \pm \\
(33.25)\end{array}$ & $\begin{array}{l}24.76 \pm \\
(23.62)\end{array}$ & $\begin{array}{r}30.43 \pm \\
(23.82)\end{array}$ \\
\hline & $>80$ & $\begin{array}{l}10.83 \pm \\
(15.67)\end{array}$ & $\begin{array}{l}14.08 \pm \\
(24.58) \\
\end{array}$ & $\begin{array}{c}8.84 \pm \\
(14.96)\end{array}$ & $\begin{array}{c}10.64 \pm \\
(16.14)\end{array}$ \\
\hline & $\begin{array}{c}\mathrm{T} \\
\text { Statistic }\end{array}$ & 9.27 & 2.15 & 10.16 & 10.31 \\
\hline
\end{tabular}

\begin{tabular}{|c|c|c|c|c|c|c|c|}
\hline \multirow{7}{*}{ 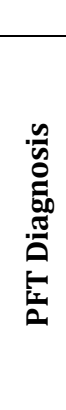 } & P value & 0.0 & \multicolumn{2}{|c|}{0.03} & 0.0 & \multicolumn{2}{|c|}{0.0} \\
\hline & Normal & $\begin{array}{l}10.57 \pm \\
(16.62)\end{array}$ & \multicolumn{2}{|c|}{$\begin{array}{l}10.55 \pm \\
(20.78)\end{array}$} & $\begin{array}{c}6.61 \pm \\
(11.75)\end{array}$ & \multicolumn{2}{|c|}{$\begin{array}{c}8.42 \pm \\
(13.49)\end{array}$} \\
\hline & $\begin{array}{c}\begin{array}{c}\text { Obstruct } \\
\text { ion }\end{array} \\
\end{array}$ & $\begin{array}{l}20.90 \pm \\
(19.28)\end{array}$ & \multicolumn{2}{|c|}{$\begin{array}{l}43.46 \pm \\
(30.67)\end{array}$} & $\begin{array}{l}24.20 \pm \\
(20.36)\end{array}$ & \multicolumn{2}{|c|}{$\begin{array}{l}29.40 \pm \\
(20.62)\end{array}$} \\
\hline & $\begin{array}{c}\text { Restricti } \\
\text { on }\end{array}$ & $\begin{array}{l}26.17 \pm \\
(22.67)\end{array}$ & \multicolumn{2}{|c|}{$\begin{array}{l}36.08 \pm \\
(31.23)\end{array}$} & $\begin{array}{l}21.70 \pm \\
(21.61)\end{array}$ & \multicolumn{2}{|c|}{$\begin{array}{l}26.16 \pm \\
(21.83)\end{array}$} \\
\hline & Mixed & $\begin{array}{c}36.84 \pm \\
23.58\end{array}$ & \multicolumn{2}{|c|}{$\begin{array}{c}60.34 \pm \\
30.99\end{array}$} & $\begin{array}{l}34.79 \pm \\
26.49\end{array}$ & \multicolumn{2}{|c|}{$\begin{array}{l}42.94 \pm \\
24.27\end{array}$} \\
\hline & $\mathrm{F}$ & 33.11 & \multicolumn{2}{|c|}{64.12} & 40.47 & \multicolumn{2}{|c|}{60.47} \\
\hline & \begin{tabular}{|l|}
$\mathrm{P}$ value \\
\end{tabular} & 0.0 & \multicolumn{2}{|c|}{0.0} & 0.0 & \multicolumn{2}{|c|}{0.0} \\
\hline \multicolumn{8}{|c|}{$\begin{array}{l}\text { Table 3. Mean SGRQ Scale Scores by Demographic and } \\
\text { Clinical Characteristics of the Study Population }\end{array}$} \\
\hline \multirow{2}{*}{\multicolumn{2}{|c|}{ PFT Diagnosis }} & \multicolumn{2}{|c|}{ Sex } & \multirow{2}{*}{ Total } & \multirow{2}{*}{\multicolumn{2}{|c|}{\begin{tabular}{|c|} 
Chi-Square \\
Statistic \\
\end{tabular}}} & \multirow{2}{*}{$\begin{array}{c}\mathbf{P} \\
\text { value }\end{array}$} \\
\hline & & Male & Female & & & & \\
\hline \multicolumn{2}{|c|}{ Normal } & 95 & 57 & 152 & \multirow{5}{*}{\multicolumn{2}{|c|}{22.02}} & \\
\hline & active & 29 & 17 & 46 & & & \\
\hline & $\begin{array}{l}\text { ctive } \\
\text { ase }\end{array}$ & 69 & 86 & 155 & & & 0.00 \\
\hline Mix & lisease & 66 & 24 & 90 & & & \\
\hline & tal & 259 & 184 & 443 & & & \\
\hline & & tion & $\begin{array}{l}\text { etwee } \\
\text { Funct }\end{array}$ & end & & & \\
\hline
\end{tabular}

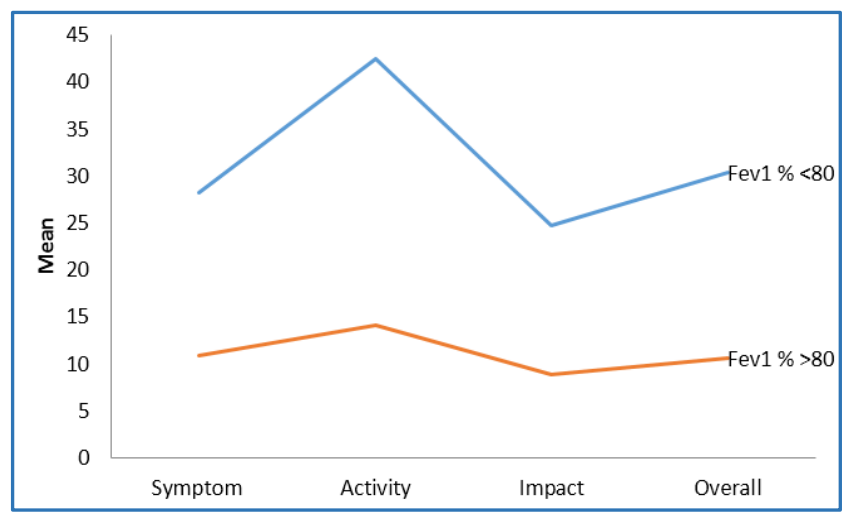

Graph 1. Comparison between FEV1\% and SGRQ Scores

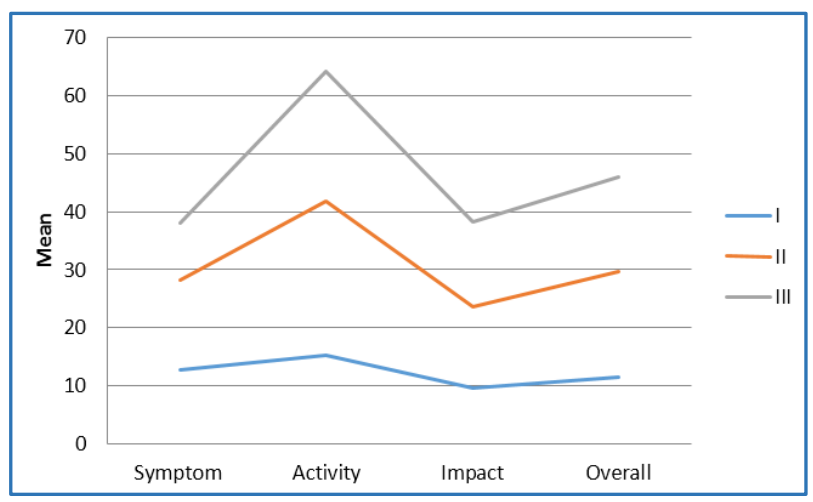

Graph 2. Comparison between Chest Radiograph Grades and SGRQ Scores

\section{DISCUSSION}

There are very few studies, which have tried to assess the quality of life once that patient has successfully completed treatment for pulmonary tuberculosis. In our study of the total of 443 patients, males have outnumbered females. This finding is consistent with the experience of Horton $\mathrm{KC}$ et al, where it was seen that prevalence of Tuberculosis is significantly higher among men in low- and middle-income countries. 10 
In our study when BMI was grouped into various categories, it was found that majority of patients fell in either the normal or underweight category 209 (47.20\%) and 207 (46.70\%). In National Health Survey 4 (2015 - 2016) from district fact sheet, Satara was shown that $30.5 \%$ females and $24.7 \%$ males were in underweight age group. In our study majority of females 92 (50\%) were in underweight category, while $44.40 \%$ males fell in underweight category and it was not statistically significant.

Abnormalities in lung function post pulmonary tuberculosis is an unrecognised cause of chronic lung disease worldwide. ${ }^{11}$ In this study, the predominant lung function abnormality observed was restrictive followed by mixed pattern similar to other published studies.3,11,12 Our findings have shown that females had more restrictive type of disease compared to males (Table 4). In a study by Manji et al on patients on active tuberculosis treatment showed that obstruction was the predominant abnormality followed by mixed and restrictive pattern. ${ }^{13}$

Lung function impairment in the present study were not significantly high among smokers. Difference in lung function impairment between smokers and non-smokers was statistically not significant. The published studies on lung function impairments and smoking in PTB patients show mixed results. $14,15,16$

The SGRQ scores were higher in this study, which suggests an impairment in the quality of life and this has been observed with various other studies done among post pulmonary tuberculosis patients. 7,17

The normative values for a general population studied in Spain recommended in SGRQ manual is used for comparison as the data pertaining to SGRQ scores in general population in India is not available. The symptom, activity and impact scores observed in our study were 22.44, 33.02 and 19.44 respectively as compared to normal scores of 12,9 and 2 on a scale of 100.18 These findings suggest that the scores of the treated PTB patients were high (indicating worse status) (Table 2).

Similar to previous SGRQ studies in pulmonary tuberculosis patients, the impact score was lower than that of symptom and activity. ${ }^{7}$

The SGRQ scores were compared with various other parameters (Table 3). The relation between SGRQ and gender were not statistically significant. SGRQ scores and chest x-ray findings were found to be statistically significant with worsening of SGRQ scores with higher grades on chest x-ray. Compared to impact and symptom scores, the activity score was most affected as the severity on the chest x-ray findings worsened (Graph 2).

On comparing FEV1\% with SGRQ scores, it was found that the patients with FEV1\% less than $80 \%$ predicted had higher SGRQ scores as compared to those with FEV1\% more than $80 \%$. Here, again the activity scores were more impaired as compared to the symptom and impact scores and it was found to be statistically significant (Graph 1 ).

SGRQ scores were compared to various lung function abnormalities. It was found that the activity scores are the most affected compared to symptom and impact scores in all three abnormal lung function categories. Those with mixed abnormality on spirometry had higher SGRQ scores and similarly the activity scores were most affected in these group of patients. Those with restriction in their spirometry had better SGRQ scores as compared to obstruction and mixed pathology. The above analysis was found to be statistically significant.

Limitations of the study: This cross-sectional study was restricted to Satara district and hence the generalisability of the results is limited. Accuracy of data collected is questionable. Selection bias could have happened. Radiological analysis was done using chest x-ray, as better radiological imaging such as CT chest scan would have been more sensitive in diagnosing radiological abnormalities.

\section{CONCLUSION}

Patients who have suffered from pulmonary tuberculosis have poor quality of life scores as compared to the normal population. The scores were worse in those who have significant lung damage on radiograph. Similarly, quality of life scores were higher in those with lung function abnormalities on spirometry. The activity score is more affected than the symptom and impact scores. Those with mixed abnormality on spirometry did worse. Thus, all patients post pulmonary tuberculosis should undergo pulmonary rehabilitation for better quality of life. It should be addressed as a part of the RNTCP programme. After a patient is declared cured, he/she should receive preventive and promotive measures like pranayama, deep breathing exercises, vaccination against respiratory infections like influenza and micronutrient supplements. Should there be any respiratory infection in the family, these vulnerable persons should be protected by home isolation and use of masks. If they get infected they should receive prompt antibiotic and in case of obstructive airway disease inhalation treatment.

\section{Funding}

Project was joint venture between RNTCP and Krishna Institute of Medical Sciences Deemed University and was funded by RNTCP.

\section{Ethical Approval}

The study was approved by the Institutional Ethics Committee.

\section{ACKNOWLEDGEMENTS}

The study could not have been possible without the active participation of all the Medical Officers of Taluk Health Centres and Primary Health Centres in Satara. We are also thankful to Bella Devaleenal and Sriram Selvaraju for helping in finalisation of the protocol.

\section{REFERENCES}

[1] Zhou C, Nagayama N, Ohtsuka Y, et al. Long-term study of patients with sequelae of pulmonary tuberculosis after pneumonectomy-obstructive impairment and its causes. The Japanese Journal of Thoracic Diseases: Nihon Kyobu Shikkan Gakkai Zasshi 1995;33(4):41621.

[2] Jones R, Kirenga BJ, Katagira W, et al. A pre-post intervention study of pulmonary rehabilitation for adults with post-tuberculosis lung disease in Uganda. International Journal of Chronic Obstructive Pulmonary Disease 2017;12:3533-9. 
[3] Pasipanodya JG, Miller TL, Vecino M, et al. Pulmonary impairment after tuberculosis. Chest 2007;131(6):1817-24.

[4] Hershkovitz I, Donoghue HD, Minnikin DE, et al. Detection and molecular characterization of 9,000year-old Mycobacterium tuberculosis from a Neolithic settlement in the Eastern Mediterranean. PLoS One 2008;3(10):e3426.

[5] McKenna SP. Measuring patient-reported outcomes: moving beyond misplaced common sense to hard science. BMC Med 2011;9:86.

[6] Guo N, Marra CA, Marra F, et al. Health state utilities in latent and active tuberculosis. Value Health 2008;11(7):1154-61.

[7] Rekha BVV, Ramachandran R, Rao KKV, et al. Assessment of long term status of sputum positive pulmonary TB patients successfully treated with short course chemotherapy. Indian Journal of Tuberculosis 2009;56(3):132-40.

[8] Willcox PA, Ferguson AD. Chronic obstructive airways disease following treated pulmonary tuberculosis. Respir Med 1989;83(3):195-8.

[9] Brusasco EV, Crapo R, Viegi G, et al. Series "ATS/ERS task force: standardisation of lung function testing". Eur Res J 2005;26(2):319-38.

[10] Horton KC, MacPherson P, Houben RM, et al. Sex differences in tuberculosis burden and notifications in low-and middle-income countries: a systematic review and meta-analysis. PLoS Medicine 2016;13(9):e1002119.
[11] Panda A, Bhalla AS, Sharma R, et al. Correlation of chest computed tomography findings with dyspnea and lung functions in post-tubercular sequelae. Lung India: official organ of Indian Chest Society 2016;33(6):592-9.

[12] Vijayan VK, Rajkumar C, Kailash N, et al. Cardiopulmonary status of treated cases of pulmonary tuberculosis. Lung India 1982:1(2):21-3.

[13] Manji M, Shayo G, Mamuya S, et al. Lung functions among patients with pulmonary tuberculosis in Dar es Salaam-a cross-sectional study. BMC Pulmonary Medicine 2016;16(1):58.

[14] Lee BH, Lee JH, Kim KC, et al. Post-tuberculosis destroyed lung: clinical characteristics and healthrelated quality of life measurement. Chest 2007;132:6398.

[15] Krishna K, Bond S, Arvinli M, et al. Pulmonary function in treated tuberculosis; a long term follow-up. Am Rev Respir Dis 1977;115:402.

[16] Di Naso FC, Pereira JS, Schuh SJ, et al. Functional evaluation in patients with pulmonary tuberculosis sequelae. Rev Port Pneumol 2011;17(5):216-21.

[17] Pasipanodya JG, Miller TL, Vecino M, et al. Using the St. George respiratory questionnaire to ascertain health quality in persons with treated pulmonary tuberculosis. Chest 2007;132(5):1591-8.

[18] Jones PW, Spencer S, Adie S. The St. George's respiratory questionnaire Manual. Version 2.1. Dated 29.5.2003. 